\title{
Laparoscopic versus open wedge resection for gastrointestinal stromal tumors of the stomach: a meta-analysis
}

\author{
Zhangwei Yang ${ }^{1}$, Pingting $\mathrm{Li}^{2}$, Yiren $\mathrm{Hu}^{1}$ \\ ${ }^{1}$ Department of General Surgery, Wenzhou People's Hospital, Wenzhou, China \\ ${ }^{2}$ Department of Operation Room, The First Affiliated Hospital of Wenzhou Medical University, Wenzhou, China
}

Videosurgery Miniinv 2019; 14 (2): 149-159

DOI: https://doi.org/10.5114/wiitm.2018.79933

\begin{abstract}
Introduction: With the rapid development of minimally invasive surgery, laparoscopic (LAP) wedge resection has become the first-choice treatment for primary gastrointestinal stromal tumors (GISTS) of the stomach.

Aim: To investigate the safety and feasibility of LAP wedge resection and the choice of surgical treatment for GISTS of the stomach through a meta-analysis and systematic review.

Material and methods: The literature was widely searched for comparative studies on open (OPEN) and LAP wedge resection for GISTs published before April 2017. The articles were selected after quality assessment.

Results: Ten reports met the inclusion criteria, with a total sample size of 485 cases. The operation time was similar between the 2 groups (weighted mean difference (WMD): $8.67 \mathrm{~min}, 95 \%$ confidence interval (CI): -8.60 to 25.94 , $p=0.33)$. However, LAP resulted in less blood loss (WMD $-32.20 \mathrm{ml}, 95 \% \mathrm{Cl}:-56.15$ to $-8.26, p<0.01)$, earlier time to flatus (WMD -1.48 days, $95 \% \mathrm{Cl}:-1.90$ to $-1.06, p<0.01)$ and to an oral diet (WMD -1.50 days, $95 \% \mathrm{Cl}:-2.25$ to $-0.47, p<0.01$ ), shorter hospital stay (WMD -2.03 days, $95 \% \mathrm{Cl}:-2.68$ to $-1.38, p<0.01$ ), and a decreased overall complication rate (relative risk: $0.48,95 \% \mathrm{Cl}: 0.25-0.89, p=0.01$ ) compared with OPEN. Moreover, long-term follow-up findings indicated no obvious difference between the 2 groups.

Conclusions: The use of LAP wedge resection for suitable cases is safe and feasible because it causes less blood loss and fewer overall complications and enables faster recovery.
\end{abstract}

Key words: laparoscopic surgery, systematic review, meta-analysis, open surgery, wedge resection, gastric gastrointestinal stromal tumor.

\section{Introduction}

Gastrointestinal stromal tumors (GISTs) are among the most common mesenchymal tumors. They are usually observed in the gastrointestinal tract, and the site of origin is frequently the stomach $[1,2]$. The definitive treatment for localized primary GISTs is mainly surgical resection with a negative margin. Instead of formal organ resection, local excision is commonly selected as the surgical procedure because the incidence of lymph node metastasis is extremely low in these cases [3]. As a result, most surgeons perform wedge resection of the stomach for GISTs. According to the guidelines of the National Comprehensive Cancer Network (NCCN), laparoscopic (LAP) surgery may be considered for GISTs of the stomach. However, LAP surgical procedures are likely to increase the risk of tumor rupture. With the rapid development of minimally invasive surgery, including laparoscopy, gasless laparoscopy, single-incision laparoscopy, and LAP-assisted technology, LAP wedge resection has become the first-choice treat- 
ment for primary GISTs of the stomach $[4,5]$. To date, numerous previous studies have analyzed and compared open (OPEN) and LAP wedge resection in terms of operation time, blood loss, time to oral diet, time to first flatus, and overall complications.

\section{Aim}

The present study aimed to investigate the safety and feasibility of LAP wedge resection and the choice of surgical treatment for GISTs of the stomach through a meta-analysis and systematic review.

\section{Material and methods}

\section{Search strategy}

In this review, the Embase, PubMed, Web of Science, and Cochrane Library databases were searched for studies comparing OPEN and LAP wedge resection of the stomach for GISTs published between April 1996 and April 2017. The following keywords were used: "laparoscopy", "gastrointestinal stromal tumor", and "open wedge resection". The search was restricted to articles written in English. After de-duplication, a total of 304 studies were found. The abstracts of the articles were read briefly to exclude irrelevant studies. Finally, 38 articles met the requirements and their full contents were reviewed.

\section{Study selection}

Comparative, peer-reviewed studies on OPEN and LAP wedge resection for GISTs for which the full content of the paper was accessible were considered to meet the inclusion criteria. When 2 or more studies were from the same organization, the latest one or the study that included the most relevant information (if the studies were conducted during the same period) was selected. Studies with the following features were excluded: GISTs outside of the stomach, non-wedge resection, data that are difficult to collect and analyze, and lack of clearly demonstrated results.

\section{Data extraction and quality assessment}

Two researchers independently extracted the data, and disagreements were resolved through a discussion. The details of each study, including the authors, area, research center, sample size, treatment factors (e.g., surgical method and whether imatinib was used), perioperative details (e.g., approximated blood loss, operation time, time to first flatus, time to oral diet, and hospital stay), postoperative complications, recurrence, and mortality, were recorded. In addition, the Newcastle-Ottawa Scale (NOS), a quality assessment tool, was applied to evaluate the quality of the included studies. Studies with a score of 6 or higher were considered methodologically reasonable.

\section{Statistical analysis}

In this study, the weighted mean difference (WMD) was applied to evaluate the constant variables and risk ratio (RR) was employed to analyze dichotomous variables. If the study provided medians and ranges instead of means and standard deviations (SDs), the means and SDs were estimated as described by Hozo et al. [6]. The random-effects model was applied according to the method of DerSimonian and Laird [7]. Statistical heterogeneity was evaluated according to the Higgins $P$ statistic, and data with significant heterogeneity were removed. Potential publication bias was determined by conducting informal visual inspection of funnel plots on the basis of the hospital stay and complications. Review Manager version 5.3 (RevMan 5.3; The Nordic Cochrane Centre, Copenhagen, Denmark) was used for all data analyses in this study.

\section{Results}

\section{Selected studies}

A total of 304 citations were obtained from a variety of electronic bibliographies. The titles and abstracts were first read briefly to exclude articles with no comparison between OPEN and LAP. Consequently, 38 comparative studies remained, among which 22 were further excluded because they failed to meet the inclusion criteria. Finally, 10 observational studies in English, for which the full text was available, remained. Figure 1 shows our search strategy including the reasons for excluding studies.

\section{Study characteristics and quality}

A total of 485 patients were enrolled, 252 of whom underwent OPEN (52\%) and 233 underwent LAP (48\%). They represented an international cohort of patients as data were collected from 7 countries and regions, including Japan, the United States, It- 


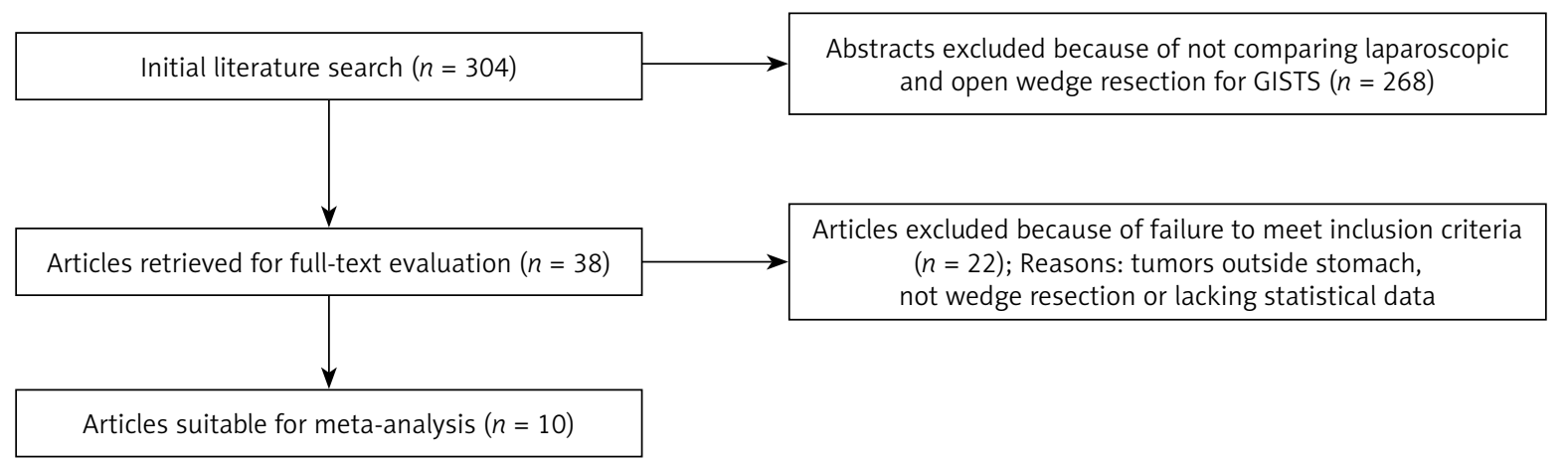

Figure 1. Flow chart of literature search strategies

aly, France, China, Singapore, and Taiwan. Table lists the features of the included studies, whereas Table II shows the quality of evaluation based on NOS. In general, the quality of the included studies was satisfactory (6 stars, 4 studies; 7 stars, 1 study; 8 stars, 1 study; 9 stars, 4 studies).

\section{Evidence from primary outcomes}

The operation time was reported in all 10 studies. On the basis of the existing analysis, no significant difference was observed in operation time (WMD $=8.67 \mathrm{~min} ; 95 \%$ confidence interval $(\mathrm{Cl}):-8.60$ to
25.94; $p=0.33$ ) (Figure 2). Blood loss was reported in 8 studies. Compared with the OPEN group, the LAP group had less blood loss (WMD $-32.20 \mathrm{ml}$, $95 \% \mathrm{Cl}:-56.15$ to $-8.26 \mathrm{ml}, p<0.01$ ) (Figure 3 ), earlier time to flatus (WMD -1.50 days, $95 \% \mathrm{Cl}:-2.25$ to $-0.47, p<0.01$ ) (Figure 4), earlier time to oral diet (WMD -1.48 days, $95 \% \mathrm{Cl}:-1.90$ to $-1.06, p<0.01$ ) (Figure 5), and faster recovery of bowel function. Among 9 studies, the LAP group had shorter hospital stay (WMD -2.03 days, $95 \% \mathrm{Cl}:-2.68$ to $-1.38, p<$ 0.01) (Figure 6).

The rate of postoperative complications was significantly lower in the LAP group than in the OPEN

Table I. Summary of studies included in the meta-analysis

\begin{tabular}{|c|c|c|c|c|c|c|c|c|c|c|}
\hline \multirow[t]{2}{*}{ Author } & \multirow[t]{2}{*}{ Region } & \multirow[t]{2}{*}{ Year } & \multirow{2}{*}{$\begin{array}{l}\text { Study } \\
\text { period }\end{array}$} & \multicolumn{2}{|c|}{ Sample size } & \multirow{2}{*}{$\begin{array}{c}\text { Conversion } \\
(\%)\end{array}$} & \multicolumn{2}{|c|}{ Follow-up [months] } & \multicolumn{2}{|c|}{ Recurrence } \\
\hline & & & & LAP & OPEN & & LAP & OPEN & LAP & OPEN \\
\hline Wu et al. & Taiwan & 2010 & $2006-2008$ & 15 & 13 & NR & \multicolumn{2}{|c|}{ NR } & \multicolumn{2}{|c|}{ NR } \\
\hline $\begin{array}{l}\text { Mochizuki } \\
\text { et al. }\end{array}$ & Japan & 2006 & $2000-2004$ & 12 & 10 & NR & $26(6-53)$ & $26(6-53)$ & 0 & 0 \\
\hline $\begin{array}{l}\text { Karakousis } \\
\text { et al. }\end{array}$ & American & 2011 & 1998-2009 & 40 & 40 & 22.5 & $28(0.3-70)$ & $43(0.1-139)$ & 1 & 1 \\
\hline $\begin{array}{l}\text { Hsiao } \\
\text { et al. }\end{array}$ & Taiwan & 2014 & 2002-2012 & 18 & 21 & NR & $3.1(1.4-11.1)$ & $5.6(1.0-11.1)$ & 1 & 0 \\
\hline $\begin{array}{l}\text { Angelis } \\
\text { et al. }\end{array}$ & France & 2014 & 2000-2010 & 25 & 25 & NR & $48.7(24-84)$ & $44.9(14-72)$ & 2 & 1 \\
\hline $\begin{array}{l}\text { Ishikawa } \\
\text { et al. }\end{array}$ & Japan & 2006 & 1993-2004 & 14 & 7 & NR & $60.2(5-119)$ & $61.3(3-130)$ & 2 & 1 \\
\hline $\begin{array}{l}\text { Shimizu } \\
\text { et al. }\end{array}$ & Japan & 2002 & $1995-2000$ & 11 & 8 & 0 & & & & $R$ \\
\hline $\begin{array}{l}\text { Catena } \\
\text { et al. }\end{array}$ & Italy & 2007 & 2001-2006 & 21 & 25 & NR & $35(5-58)$ & $91(80-136)$ & 0 & 1 \\
\hline Goh et al. & Singapore & 2010 & 2001-2009 & 14 & 39 & 7.1 & $8(3-60)$ & $21(2-72)$ & 0 & 2 \\
\hline Wan et al. & China & 2012 & 2004-2011 & 63 & 64 & NR & $29(4-89)$ & $36(4-90)$ & & R \\
\hline
\end{tabular}

$N R$ - not reported. 
Table II. Quality assessment based on the NOS for observational studies

\begin{tabular}{|c|c|c|c|c|c|c|c|c|c|}
\hline \multirow[t]{2}{*}{ Author } & \multicolumn{4}{|c|}{ Selection } & \multirow{2}{*}{$\begin{array}{l}\text { Compara- } \\
\text { bility }\end{array}$} & \multicolumn{3}{|c|}{ Outcomes } & \multirow[t]{2}{*}{ Total } \\
\hline & $\begin{array}{c}\text { Repre- } \\
\text { sentative- } \\
\text { ness of } \\
\text { exposed } \\
\text { cohort }\end{array}$ & $\begin{array}{l}\text { Selection } \\
\text { of non- } \\
\text { exposed } \\
\text { cohort }\end{array}$ & $\begin{array}{l}\text { Ascertain- } \\
\text { ment of } \\
\text { exposure }\end{array}$ & $\begin{array}{l}\text { Outcome } \\
\text { not pres- } \\
\text { ent at the } \\
\text { start of } \\
\text { the study }\end{array}$ & & $\begin{array}{l}\text { Assess- } \\
\text { ment of } \\
\text { outcomes }\end{array}$ & $\begin{array}{l}\text { Length of } \\
\text { follow-up }\end{array}$ & $\begin{array}{c}\text { Adequacy } \\
\text { of fol- } \\
\text { low-up }\end{array}$ & \\
\hline Wu et al. & * & * & * & * & * & * & & & 6 \\
\hline $\begin{array}{l}\text { Mochizuki } \\
\text { et al. }\end{array}$ & * & * & * & * & ** & * & & & 7 \\
\hline $\begin{array}{l}\text { Karakousis } \\
\text { et al. }\end{array}$ & * & * & * & * & ** & * & * & * & 9 \\
\hline Hsiao et al. & * & * & * & * & * & * & & & 6 \\
\hline $\begin{array}{l}\text { Angelis } \\
\text { et al. }\end{array}$ & * & * & * & * & ** & * & * & * & 9 \\
\hline $\begin{array}{l}\text { Ishikawa } \\
\text { et al. }\end{array}$ & * & * & * & * & * & * & * & * & 8 \\
\hline $\begin{array}{l}\text { Shimizu } \\
\text { et al. }\end{array}$ & * & * & * & * & * & * & & & 6 \\
\hline $\begin{array}{l}\text { Catena } \\
\text { et al. }\end{array}$ & * & * & * & * & ** & * & * & * & 9 \\
\hline Goh et al. & * & * & * & * & * & * & & & 6 \\
\hline Wan et al. & * & * & * & * & $* *$ & * & * & * & 9 \\
\hline
\end{tabular}

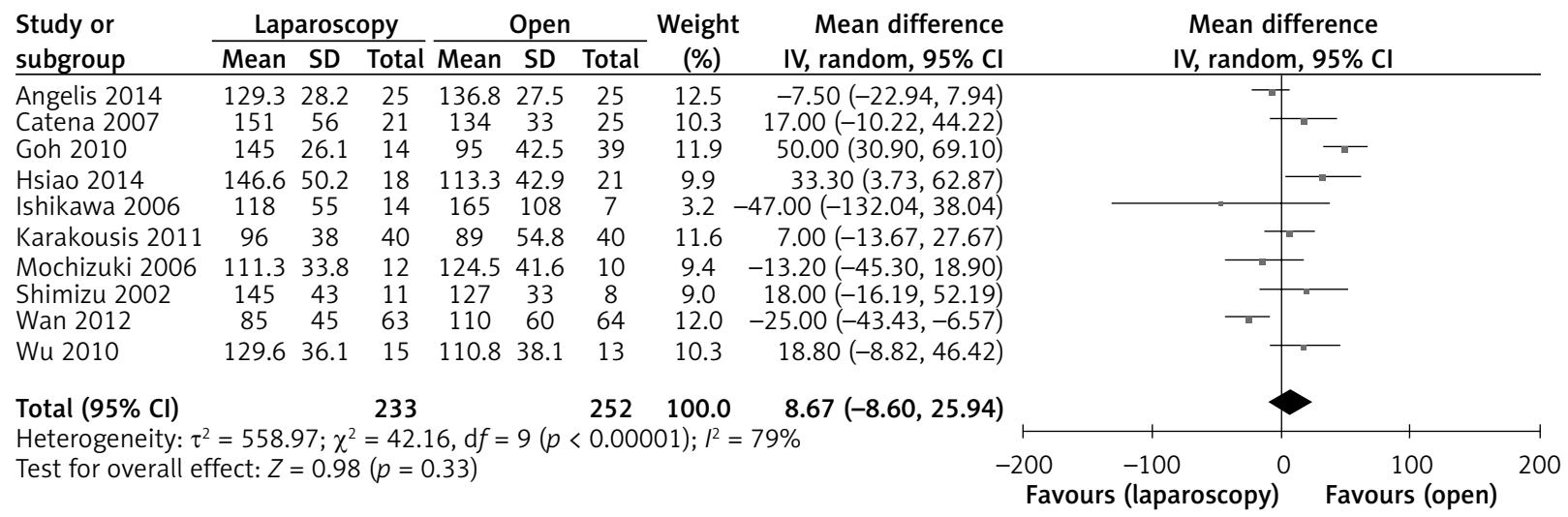

Figure 2. Meta-analysis of the pooled data operation time (minutes)

group ( $\mathrm{RR}=0.45,95 \% \mathrm{Cl}: 0.25-0.83, p=0.01)$ (Figure 7). The funnel plots in Figures 8 and 9 were symmetric, proving that no serious publication bias existed. Table III summarizes the special postoperative complications in these studies.

Tumor size was reported in all 10 studies. On the basis of the analysis of 485 resections, compared with the tumor size for OPEN, the tumor size for LAP was slightly smaller (WMD $-0.56 \mathrm{~cm}, 95 \% \mathrm{Cl}:-1.02$ to $-0.10, p=0.02$ ) (Figure 10). There were 7 studies that recorded tumor recurrence in the follow-up period. Compared with the recurrence risk of $4.2 \%$ (7 of 167) in OPEN, the risk in LAP was 3.5\% (5 of 144). Patients who underwent LAP were less likely 


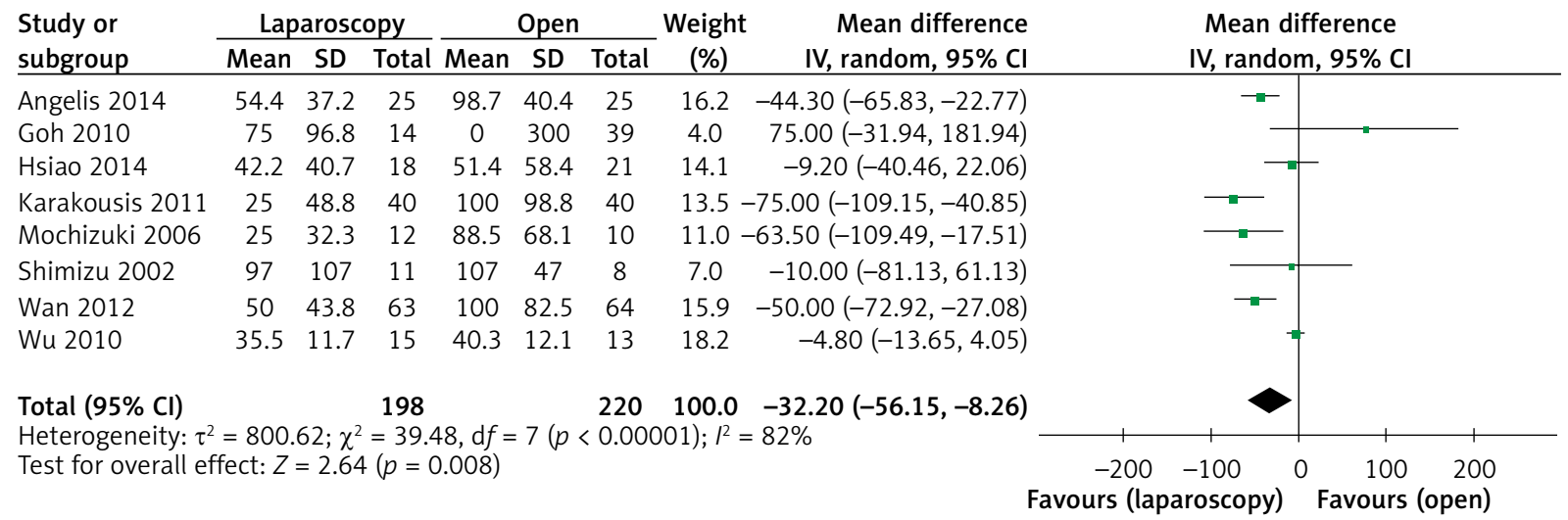

Figure 3. Meta-analysis of the pooled data intraoperative blood loss

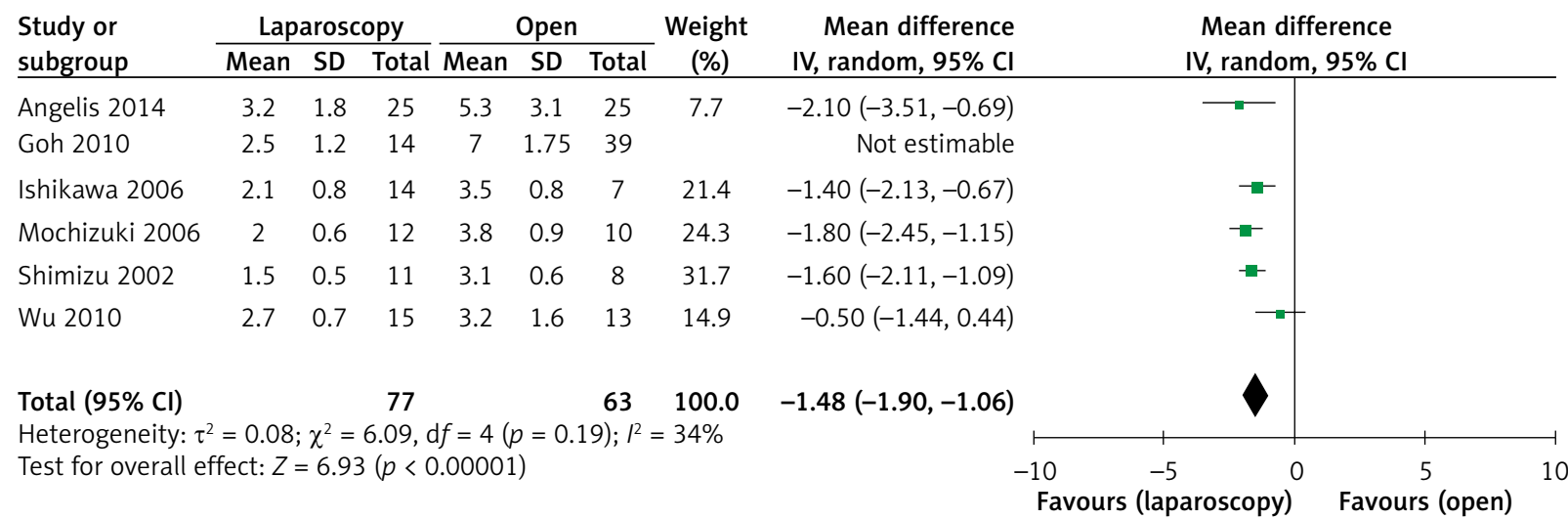

Figure 4. Meta-analysis of the pooled data time to first flatus

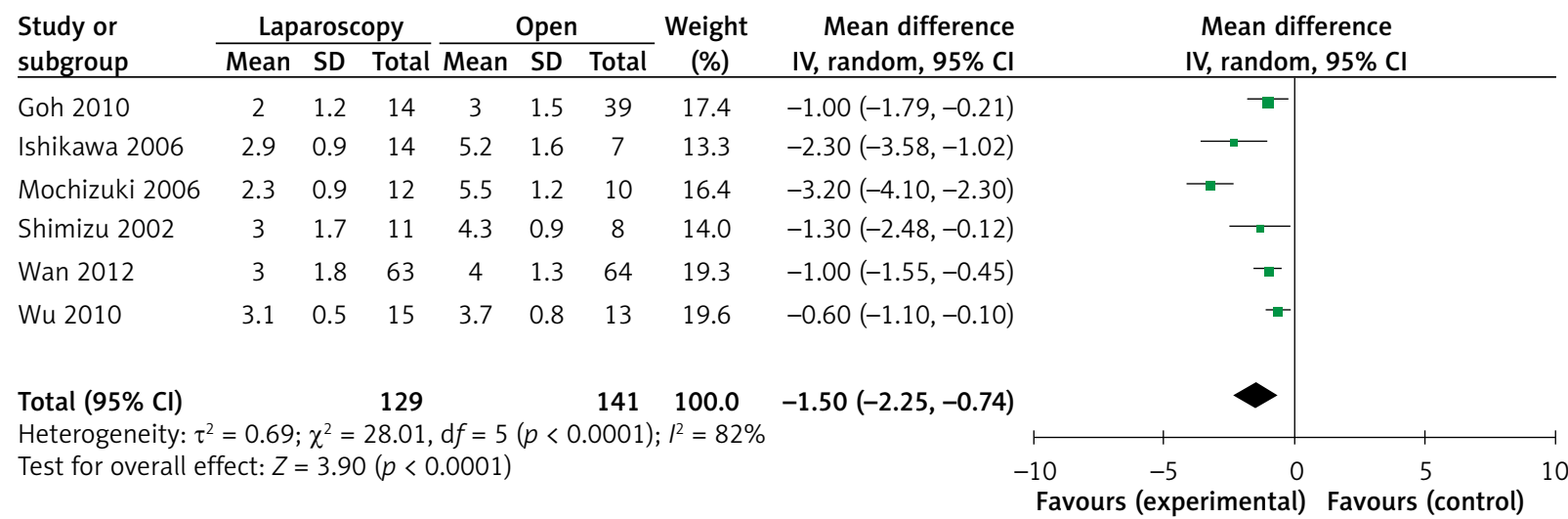

Figure 5. Meta-analysis of the pooled data time to oral intake

to develop tumor recurrence than those who underwent OPEN ( $\mathrm{RR}=0.82,95 \% \mathrm{Cl}: 0.27-2.45, p=0.72)$ (Figure 11). Table IV summarizes the data concerning special recurrence sites and recurrence patterns, as well as the survival results.

\section{Discussion}

As one of the most common mesenchymal tumors, GISTs from the gastrointestinal tract have attracted increasing attention. In $70 \%$ of cases, the stomach is the site of origin. With the develop- 


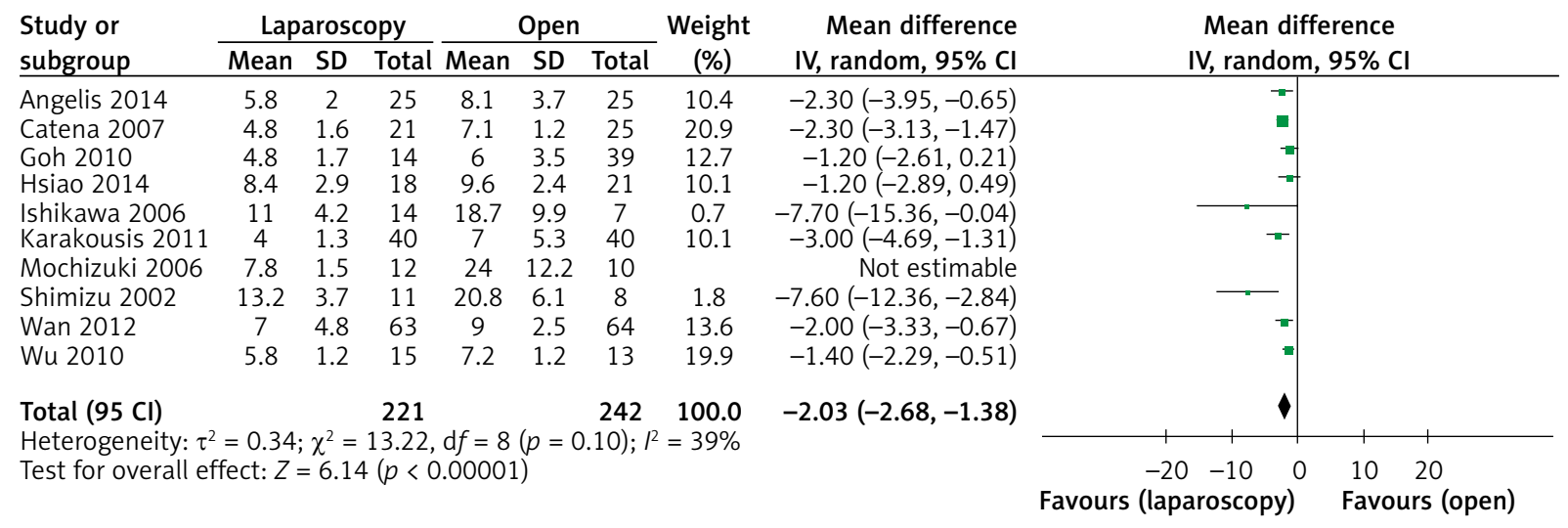

Figure 6. Meta-analysis of the pooled data hospital stay

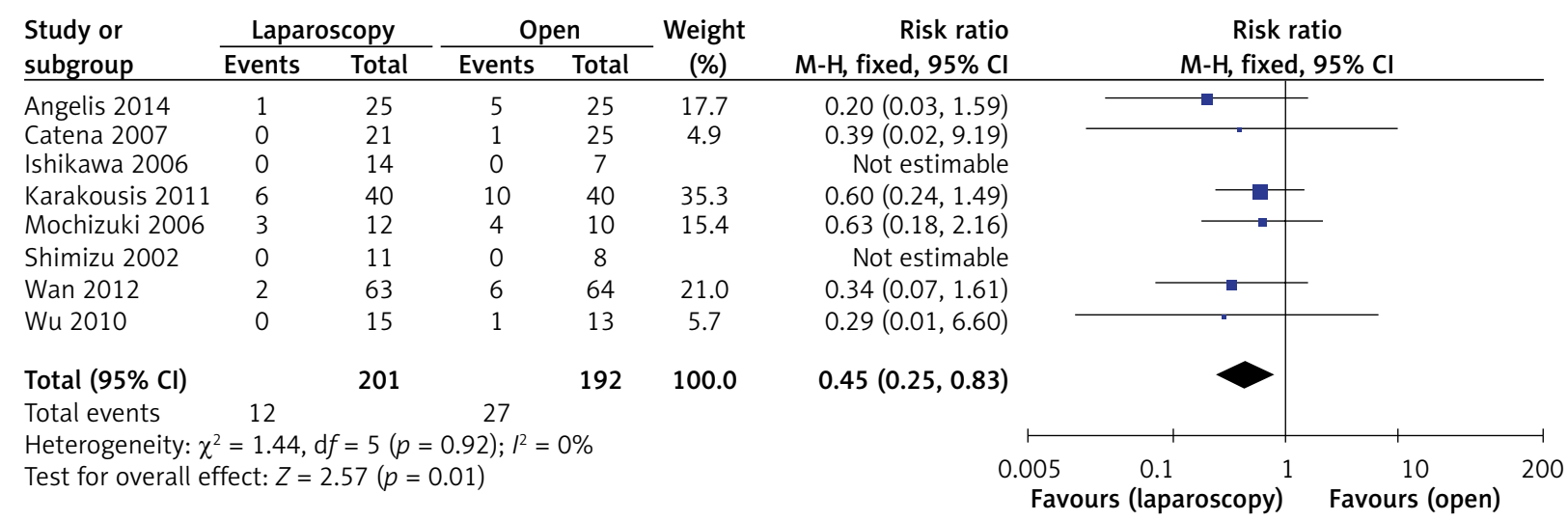

Figure 7. Meta-analysis of the pooled data overall complications

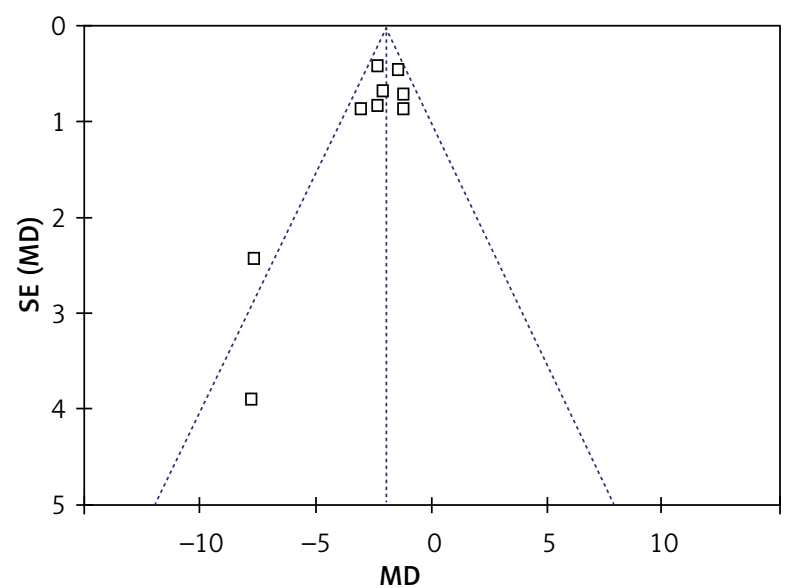

Figure 8. Funnel plot of the hospital stay

ment of new treatment methods, the importance of imatinib has been identified [1, 2]. However, in accordance with the 2010 NCCN guidelines and the European Society for Medical Oncology clinical rec-

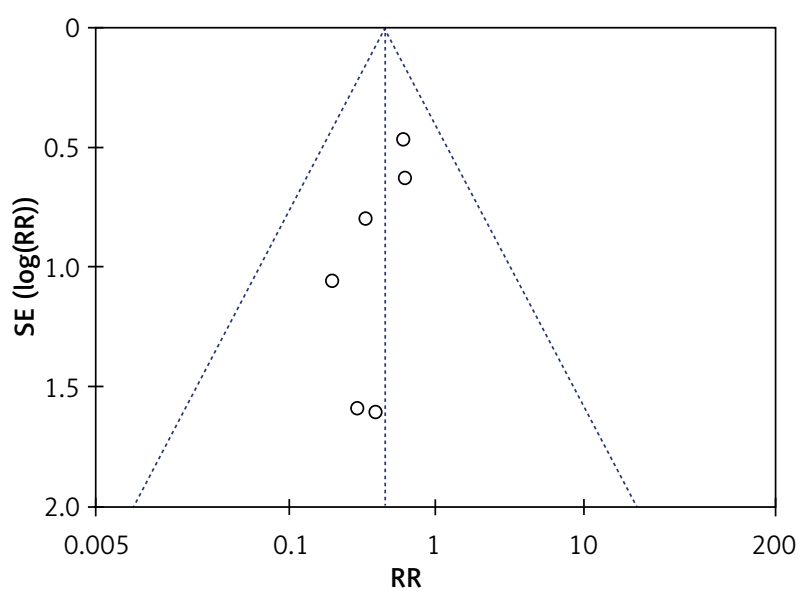

Figure 9. Funnel plot of the overall postoperative complications

ommendations in 2012, the most common treatment for primary GISTs is surgical resection without dissection of negative lymph nodes [4]. In addition, recent studies indicate that the prognosis primarily 
Table III. Systematic review of postoperative complications

\begin{tabular}{|c|c|c|}
\hline Author & LAP & OPEN \\
\hline WU et al. & None & |leus*1 \\
\hline Mochizuki et al. & $\begin{array}{l}\text { Pneumothrax }{ }^{\star} 1 \\
\text { Pneumonia*1 } \\
\text { Bowel injury }{ }^{\star} 1\end{array}$ & Did not specified ${ }^{*} 4$ \\
\hline Karakousis et al. & $\begin{array}{l}\text { Gl bleeding*1 } \\
\text { Leakage lead to abdominal collection*1 } \\
\text { Did not specified }{ }^{\star} 4\end{array}$ & $\begin{array}{l}\text { Pneumonia*1 } \\
\text { Deep venous thrombus *1 } \\
\text { Did not specified } 8\end{array}$ \\
\hline Wan et al. & $\begin{array}{c}\text { Wound infection*1 } \\
\text { Anastomosis site bleeding*1 }\end{array}$ & $\begin{array}{c}\text { Pyrexia of unknown origin*4 } \\
\text { Wound infection*1 } \\
\text { Wound dehiscence*1 }\end{array}$ \\
\hline Catena et al. & None & Wound infection*1 \\
\hline Angelis et al. & Pulmonary infection`1 & $\begin{array}{c}\text { Hemorrhage }{ }^{\star} 1 \\
\text { Wound abscess }{ }^{*} 2 \\
\text { Pulmonary infection*2 }\end{array}$ \\
\hline
\end{tabular}

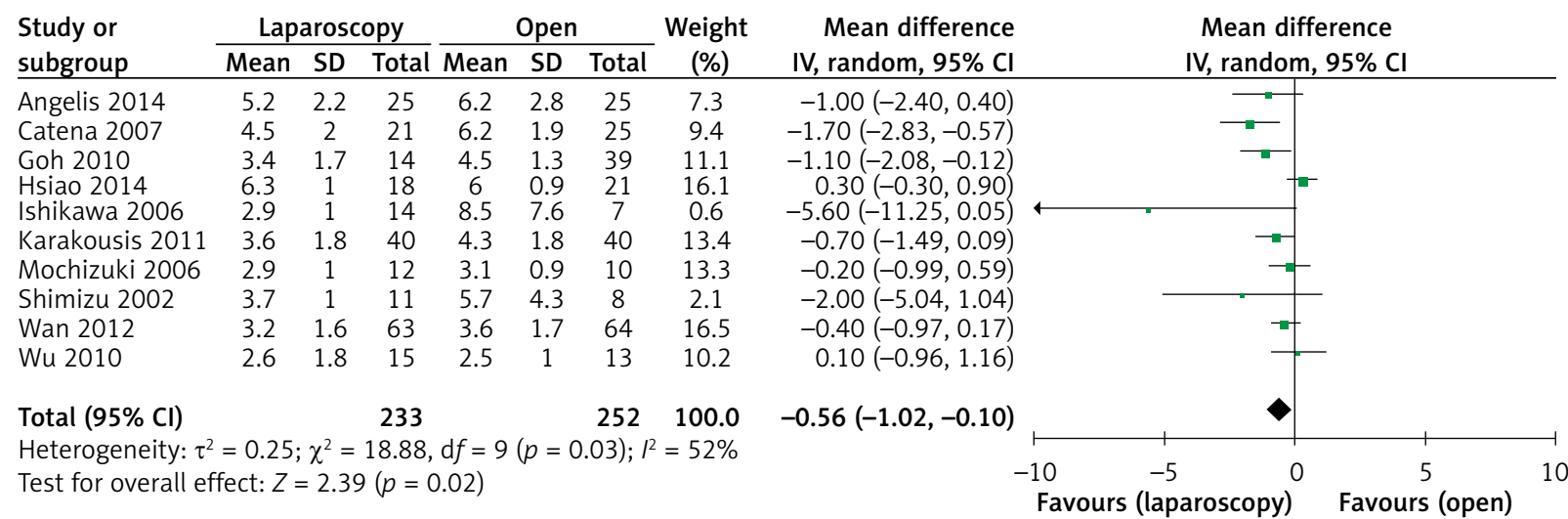

Figure 10. Meta-analysis of the pooled data tumor size

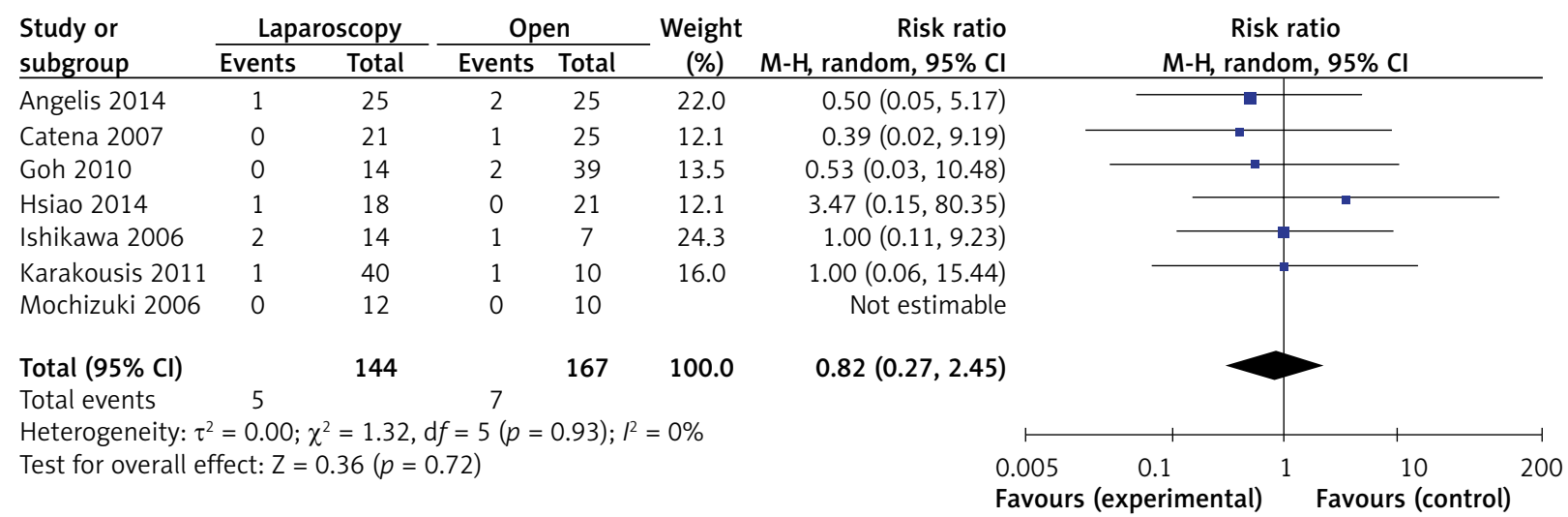

Figure 11. Meta-analysis of the pooled data tumor recurrence

depends on the histological characteristics and tumor size rather than on wide resection margins [5]. For the abovementioned reasons, wedge resection is preferred for the treatment of GISTs. Moreover, owing to advances in devices and techniques, laparoscopy is now being used in increasingly complicated 
Table IV. Summary of the recurrence patterns and survival outcomes

\begin{tabular}{|c|c|c|c|c|c|}
\hline Author & Group & Tumor size $[\mathrm{cm}]$ & Risk & Recurrence & Survival \\
\hline \multirow[t]{2}{*}{ Karakousis et al. } & Laparoscopy & 3.5 & High & Peritoneal & 4 y alive \\
\hline & OPEN & 3.5 & Moderate & Liver & 10 y alive \\
\hline Hsiao et al. & Laparoscopy & 8 & High & $4 \mathrm{~m}$ liver & 4 y alive* \\
\hline \multirow[t]{3}{*}{ Angelis et al. } & Laparoscopy & $N R$ & $N R$ & Liver & $24 \mathrm{~m}$ dead \\
\hline & OPEN & $N R$ & $N R$ & Local & Alive \\
\hline & OPEN & $N R$ & $N R$ & Liver & Alive \\
\hline \multirow[t]{3}{*}{ Ishikawa et al. } & Laparoscopy & $N R$ & Low & Local & Alive \\
\hline & Laparoscopy & 4.5 & High & Liver & $32 \mathrm{~m}$ dead \\
\hline & OPEN & 25 & High & Liver & $9 \mathrm{~m}$ dead \\
\hline Catena et al. & OPEN & $N R$ & $N R$ & $N R$ & Dead \\
\hline \multirow[t]{2}{*}{ Goh et al. } & OPEN & $N R$ & NR & $N R$ & $N R$ \\
\hline & OPEN & NR & NR & NR & NR \\
\hline
\end{tabular}

NR-not reported.

surgical procedures. Therefore, most surgeons consider LAP wedge resection as the main treatment. Meanwhile, several studies have compared between OPEN and LAP wedge resection of GISTs of the stomach. The present study attempted to compare OPEN and LAP wedge resection of GISTs of the stomach by collecting evidence in terms of patients with gastric GISTs who underwent either OPEN or LAP wedge resection and analyzed the reasons for selecting laparoscopy according to the size and location of the tumor. A total of 10 studies, comprising 485 patients, were finally included for pooled analysis.

On the basis of the existing analysis, the operation time [8-17] in the LAP group was not longer than that in the OPEN group. Possibly because of the rapid development in LAP instruments and surgical techniques, the times for closure of the trocar incision and for the establishment of pneumoperitoneum in LAP were shorter than the times for opening and closing of the laparotomy. Additionally, lymphadenectomy is not necessarily required because the probability of lymph node metastasis is low and lymphadenectomy is a time-consuming and complicated procedure. In the LAP group, blood loss [8-10, 13-17] during the operation was lower according to the pooled analysis. The application of a harmonic scalpel is beneficial in reducing blood loss. In addition, the skilled LAP operative technique, magnified small vessels, and shorter length of incision mainly contributed to reducing blood loss. Owing to the differences among studies with respect to tumor size, degree of resection, and evaluation approach, the existing research is inherently flawed and has many confounding factors. Consequently, the results on the difference in blood loss among studies should be explained cautiously.

On the basis of the pooled analysis, which is often used to assess the safety and feasibility of a surgical procedure, the number of complications [8-14, $16,17]$ was reduced in the LAP group. According to some studies, macrophages and neutrophils are possibly activated by the prolonged retraction of the intestine and the wide range of handling releases several inflammatory mediators, causing intestinal wall edema. The contraction of intestinal smooth muscle is inhibited because of the cascade of inflammatory reactions. The LAP is a minimally invasive procedure with several advantages, such as short time of abdominal cavity exposure, small incision, and less intestinal mechanical stimulation and traction, which result in moderate inflammatory reactions and facilitate early activities, thus reducing the incidence rate of adhesions, ileus, incision infection, and incisional hernia. In addition, patients undergoing LAP have less postoperative pain, which is reflected by a lower dosage or shorter duration of use of analgesics. Patients who underwent OPEN experience difficulties in coughing or in engaging in breathing exer- 
cises because of the serious pain resulting from the large incision and the application of tension sutures and abdominal bandages. Thus, these patients develop complications such as pneumonia, especially elderly patients. According to the present research, because many complications are reduced and gastrointestinal recovery is becoming faster, LAP results in a shorter time to flatus $[9,10,13,14,16,17]$ and to oral diet $[8,10,14,16,17]$ as well as to shorter postoperative hospital stays [8-14, 16, 17].

Owing to the malignant potential of GISTs, longterm survival is a crucial criterion for patients with these tumors. As for the main data, our analysis indicated that the recurrence rate after the operation $[10-13,15,17]$ is higher in OPEN than in LAP, and the difference is statistically significant. However, in certain included studies, the risk level was lower for LAP than that for OPEN, and the tumor diameter for LAP was smaller. Table IV shows all the recurrences, and indicates that patients with recurrence and those who were transferred were considered the high-risk group with no direct relationship to the operation type. As a result, with continuous improvements in technology, and on the conditions that appropriate patients are selected and operation protocols (formulated based on the standards for achieving maximal tumor removal and avoiding tumor rupture) are strictly followed, we are convinced that LAP, with its advantages owing to its minimally invasive nature, can be considered safe and feasible, with nearly the same long-lasting effect as that of laparotomy.

For the abovementioned reasons, LAP wedge resection is widely accepted by most surgeons as treatment for GISTs of the stomach, although the indications for the procedure with respect to the tumor size and location remain controversial. For LAP, the choice of tumor size should be seriously considered with the rapidly progressing techniques. According to the NCCN in 2004, only tumors $<2 \mathrm{~cm}$ in diameter are indicated for LAP. Three years later, LAP excision was allowed for tumors up to $5 \mathrm{~cm}$ in diameter. According to the guidelines of the NCCN in 2010, LAP resection is considered comparatively feasible and safe for patients with smaller and low-risk GISTs of the stomach. LAP resection may remove gastric GISTs $<5 \mathrm{~cm}$ in diameter. As for gastric GISTs $>5 \mathrm{~cm}$ in diameter, a LAP-assisted technique may be used as support. Apart from the tumor size, the tumor location also plays an important role in the selection of patients, especially for LAP wedge resec- tion of gastric GISTs. Concerning apparatus for LAP, more room is required for wedge resection on the greater curvature side because the side of the stomach is longer and bigger than that on the lesser curvature side. Moreover, some gastric GIST tumors are very large or are in close proximity to the esophagogastric junction. Hsiao et al. [15] divided the location into 2 types: easy-to-access (greater curvature side, fundus, antrum) and difficult-to-access (lesser curvature side, pylorus, cardia) sites. Their study showed that the rate of difficult-to-access tumors was not significantly different between the LAP and OPEN groups, indicating that selecting LAP to treat gastric GISTs at those difficult-to-access sites was possible in some cases. However, some researchers also pointed out that LAP is possibly not the best choice. In terms of difficult-to-access tumors, it is generally considered that it is better to hand-sew incisions instead of stapling to prevent deformity or stenosis when wedge resection is performed. In addition, using the LAP suturing technique is also challenging for most surgeons [18-20]. At present, no clear guidelines for LAP wedge resection of GISTs have been established on the basis of the size and location of the tumor.

On the basis of the abovementioned clinical issues, some researchers have proposed that proximal or distal subtotal gastrectomy is required if the distance is too close $(<1.5 \mathrm{~cm})$, with an aim to avoid postoperative gastric inlet or outlet stenosis [19]. If the distance is relatively close $(1.5-3 \mathrm{~cm})$ and the tumor is relatively large $(>5 \mathrm{~cm})$, then subtotal gastrectomy is required and should conform to the tumor radical resection principle to guarantee the incisal edge distance. In addition, GISTs can be divided into the intragastric type and the extragastric type according to the direction of the expansive growth of the mass. Extragastric tumor is associated with a less difficult resection because its intraoperative position can be easily identified and the basilar part can be better judged. However, the position of the intragastric tumor is difficult to judge because the laparoscope lacks a sense of touch. As a result, a way of combining the use of a gastroscope with a laparoscope has emerged in recent years. The intraoperative gastroscope determines the tumor position, and the curved cutter stapler is used to remove the entire tumor from the gastric wall 1-2 cm away from the tumor margin. In the case of a large mass, extragastric wedge resection may result in a wide 
gastric wall resection. In this case, the gastric wall can be cut open first to expose the tumor out of the gastric cavity (note: gastric wall incision in patients with mass rupture and internal hemorrhage may result in tumor dissemination); then, the resection should be conducted along the tumor margin from the inside of the gastric cavity with the stapler (note: a snare can be used to pull the tumor out). Finally, the gastric wall incision can be closed with sutures. This method can remove less gastric wall tissue and preserve the gastric function to a great extent. However, it can also increase the possibility of intraoperative contamination and tumor dissemination [21, 22].

Caution is needed when interpreting the results of this study for several reasons. First, all data included in the present study were extracted from non-randomized controlled trials, although randomized controlled trials (RCTs) are best-suited for a meta-analysis. Selecting high-quality RCTs for the evaluation of a new surgical intervention is challenging owing to barriers such as cultural and ethical issues, learning curve effects, unexpected or urgent conditions during the operation, and the comparatively low incidence of these tumors. Hence, inclusion of non-RCTs should only be considered for increasing the source of evidence owing to the unavailability of RCTs. Numerous related data were extracted, and the results were pooled to evaluate the safety and efficacy of LAP wedge resection of GISTs. It is possible that the meta-analysis of these data resulted in less powerful outcomes than if pure RCTs were analyzed. Second, NOS was used for the quality evaluation of studies included in the meta-analysis, although NOS was designed for the evaluation of the quality of observational studies with a checklist. However, despite the approach being applied in practice, it may be more suitable to be used for observational studies of an epidemiological nature than for non-randomized interventional studies with a surgical setting. Third, some related studies were not included in the analysis because they were written in other languages, had incomplete raw data, or had publication limitations. All of the abovementioned limitations possibly led to a non-reliable conclusion.

\section{Conclusions}

Laparoscopic wedge resection is feasible and safe for the treatment of gastric GISTs in terms of shortterm and long-term results. Compared with OPEN,
LAP is better for a certain cohort of patients, as it is a minimally invasive procedure. However, RCTs or prospective studies are required to further assess the status of LAP wedge resection for GISTs of the stomach in comparison with OPEN.

\section{Conflict of interest}

The authors declare no conflict of interest.

\section{References}

1. Miettinen M, Majidi M, Lasota J. Pathology and diagnostic criteria of gastrointestinal stromal tumors (GISTs): a review. Eur J Cancer 2002; 38 Suppl 5: S39-51.

2. Demetri GD, von Mehren M, Antonescu CR, et al. NCCN Task Force report: update on the management of patients with gastrointestinal stromal tumors. J Natl Compr Canc Netw 2010; 8 Suppl 2: S1-41.

3. DeMatteo RP, Lewis JJ, Leung D, et al. Two hundred gastrointestinal stromal tumors: recurrence patterns and prognostic factors for survival. Ann Surg 2000; 231: 51-8.

4. Rutkowski P, Wozniak A, Dębiec-Rychter M, et al. Clinical utility of the new American Joint Committee on Cancer staging system for gastrointestinal stromal tumors: current overall survival after primary tumor resection. Cancer 2011; 117: 4916-24.

5. Lee $\mathrm{CH}$, Hyun MH, Kwon YJ, et al. Deciding laparoscopic approaches for wedge resection in gastric submucosal tumors: a suggestive flow chart using three major determinants. J Am Coll Surg 2012; 215: 831-40.

6. Hozo SP, Djulbegovic B, Hozo I. Estimating the mean and variance from the median, range, and the size of a sample. BMC Med Res Methodol 2005; 5: 13.

7. Higgins JP, Thompson SG, Deeks JJ, Altman DG. Measuring inconsistency in meta-analyses. BMJ 2003; 327: 557-60.

8. Wan P, Yan C, Li C, et al. Choices of surgical approaches for gastrointestinal stromal tumors of the stomach: laparoscopic versus open resection. Dig Surg 2012; 29: 243-50.

9. Wu JM, Yang CY, Wang MY, et al. Gasless laparoscopy-assisted versus open resection for gastrointestinal stromal tumors of the upper stomach: preliminary results. J Laparoendosc Adv Surg Tech A 2010; 20: 725-9.

10. Goh BK, Chow PK, Chok AY, et al. Impact of the introduction of laparoscopic wedge resection as a surgical option for suspected small/medium-sized gastrointestinal stromal tumors of the stomach on perioperative and oncologic outcomes. World J Surg 2010; 34: 1847-52.

11. Catena F, Di Battista M, Fusaroli P, et al. Laparoscopic treatment of gastric gist: report of 21 cases and literature's review. J Gastrointest Surg 2008; 12: 561-8.

12. Karakousis GC, Singer S, Zheng J, et al. Laparoscopic versus open gastric resections for primary gastrointestinal stromal tumors (GISTs): a size-matched comparison. Ann Surg Oncol 2011; 18: 1599-605.

13. De'Angelis N, Brunetti F, Felli E, et al. Laparoscopic versus open gastric wedge resection for primary gastrointestinal tumors: 
clinical outcomes and health care costs analysis. Surg Laparosc Endosc Percutan Tech 2015; 25: 143-6.

14. Mochizuki Y, Kodera Y, Fujiwara M, et al. Laparoscopic wedge resection for gastrointestinal stromal tumors of the stomach: initial experience. Surg Today 2006; 36: 341-7.

15. Hsiao CY, Yang CY, Lai IR, et al. Laparoscopic resection for large gastric gastrointestinal stromal tumor (GIST): intermediate follow-up results. Surg Endosc 2015; 29: 868-73.

16. Shimizu S, Noshiro H, Nagai E, et al. Laparoscopic wedge resection of gastric submucosal tumors. Dig Surg 2002; 19: 169-73.

17. Ishikawa K, Inomata M, Etoh T, et al. Long-term outcome of laparoscopic wedge resection for gastric submucosal tumor compared with open wedge resection. Surg Laparosc Endosc Percutan Tech 2006; 16: 82-5.

18. Chen DL, Ke ZW. The clinical application of laparoscopic resection of gastrointestinal stromal tumor. I Laparosc Surg 2010; 15: 169-71.

19. Chen K, Zhou YC, Mou YP, et al. Systematic review and metaanalysis of safety and efficacy of laparoscopic resection for gastrointestinal stromal tumors of the stomach. Surg Endosc 2015; 29: 355-67.

20. Walsh RM, Heniford BT. Laparoendoscopic treatment of gastric stromal tumors. Semin Laparosc Surg 2001; 8: 189-94.

21. Zaydfudim V, Okuno SH, Que FG, et al. Role of operative therapy in treatment of metastatic gastrointestinal stromal tumors. J Surg Res 2012; 177: 248-54.

22. Smolarek S, Pomeroy E, Kinnarney F, Arumugasamy M. Laparoscopic resection of large gastric gastrointestinal stromal tumours. Videosurgery Miniinv 2015; 11: 31-7.

Received: 31.07 .2018 , accepted: 2.09.2018. 